\title{
From the promotion of biodiversity to the Recovery of organic waste
}

\author{
Mustapha Jammoukh ${ }^{1, *}$, Khalifa Mansouri ${ }^{1}$ and Bachir Salhi ${ }^{2}$ \\ ${ }^{1}$ Laboratory of Signals, Distributed systems and Artificial Intelligence (SSDIA), Hassan II University \\ of Casablanca, Higher Normal School of Technical Education, P.O. Box 15928820 Mohammedia, \\ Morocco. \\ ${ }^{2}$ Laboratory of Applied Mechanics and Technology (LAMAT), Mohammed V University of Rabat, \\ Higher Normal School of Technical Education P.O. Box 6207, 10100 Rabat, , Morocco.
}

\begin{abstract}
This article presents an empirical research to classify a new renewable resource material, as opposed to eco-composites, it has been neglected by the materials specialist. This classification is based on the typology of elastic behavior demonstrated by tensile tests. In addition, some identifying criterions of the usefulness of this material were examined. To justify the relevance of this classification, curves from the extension of tests focusing on the virgin material, illustrate significant results of the review. Obtained from waste, having a significant recycling possibilities and potential from renewable resources, bio-mechanically characterized loads will be injected into polymeric materials of different categories. All in the perspective of promoting changes in thermomechanical properties, whether static or dynamic; such as resistance to corrosion, heat, wear... They result in functional changes such as security, relief, coatings and stability...
\end{abstract}

\footnotetext{
* Corresponding Author：JAMOUKH@Yahoo.fr
} 


\section{Introduction}

Since 1992, Kohmei Halada has defined eco-materials [1, 2, 3] as materials contributing to the reduction of the environmental impact associated with human activities. This concept takes its meaning in the context of sustainable development and eco-design. These can be innovative materials or original combinations of known materials: materials containing fewer hazardous substances, materials from renewable resources and some industrial coproducts [4].

The latest advances in organic or inorganic materials, plant, animal or hybrid origin are in vogue in the development of " Sustainable Materials ". It will be necessary to consider the use of natural and renewable resources both at the level of matrix and loads (natural loads and plants) for composite applications by focusing on the physico-chemical properties $[5]$.

Based on these recommendations, we hope, through our research, to improve these ecocomposites by reinforcing their thermo-mechanical qualities by a load of animal origin.

By general name of charge, we mean any inert substance, added to a basic polymer, makes it possible to modify the mechanical, electrical or thermal properties in a sensitive manner, to improve the surface appearance or simply to reduce the price of returns from the processed material [6].

For a given polymer, the choice of a load is determined based on the changes you are looking for the finished object. However, in general, substances used as loads of plastics will first have to meet several requirements: compatibility with basic resin, wettability, uniformity of quality and particle size, low abrasive action, low cost... [7, 8,9$]$.

This work essentially attempts to unveil the physical performance of the virgin biomaterial found naturally so that other materials can benefit from: Hardness, Toughness, Resilience,

Heat Resistance ...

[10].

This animal-based bio-charge comes in the form of a regular thickness sheath and generally smooth surface. It is finer at its base than at its extremity. The lower part is rough on the surface and has streaks at fairly regular intervals (Figure 1). Although the "Death" this fabric is produced by the living. It is composed of proteins rich in sulfur, forming fibers. It is present on the surface of the skin in the form of scales. Once it was a valuable material, ideal for making lots of items. In mythology, this matter of abundance symbolizes perpetual profligacy, it produces much from little [11].

After its preparation in powder or in cuttings, this substance will be injected into a basic composite material and then tested to evaluate its contribution to the reinforcement of the thermo-mechanical characteristics sought on the base material after summing up and also optimizing its work [12]. To develop this new material, a set of actions will be discussed and can be categorized into four phases (Figure 1). 


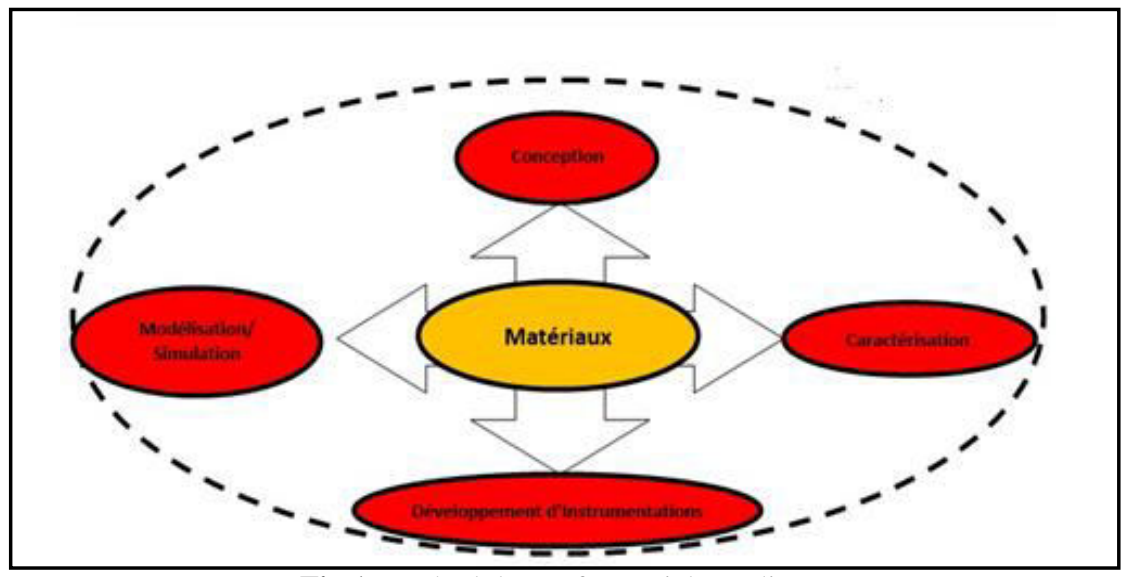

Fig.1. Methodology of materials studies.

\section{Characterization Strategy of the Virgin material}

\section{1 process for the preparation of tensile specimens}

The transformation of the sheath into bio-charge is obtained by separating it from the cornillon forming the selected substance. This material is very easy to work with, once heated and softened, it can be cracked, compressed, sawed, pierced or rotated. We can even solder parts to make them placquers [11]. This step is used to obtain specimens sample for mechanical tests by punching or cutting, particularly those for tensile tests. It can also be turned into cutters and powder to be eventually used as loads in plastic materials [6].

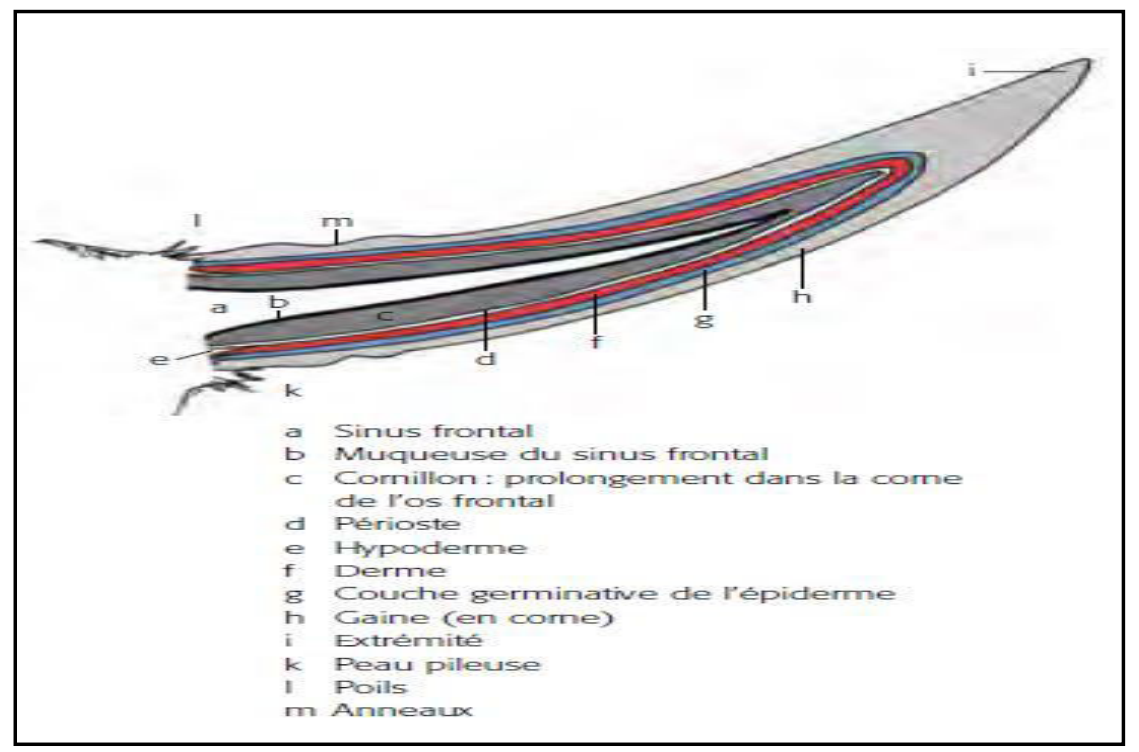

Fig. 2. Longitudinal sections of the corne.

Once heated and softened, the sheath is compressed for a quarter of an hour in a press. This phase is followed by the milling process for finishing the surface of the plate, according to ISO 527-2 (Figure 3). 


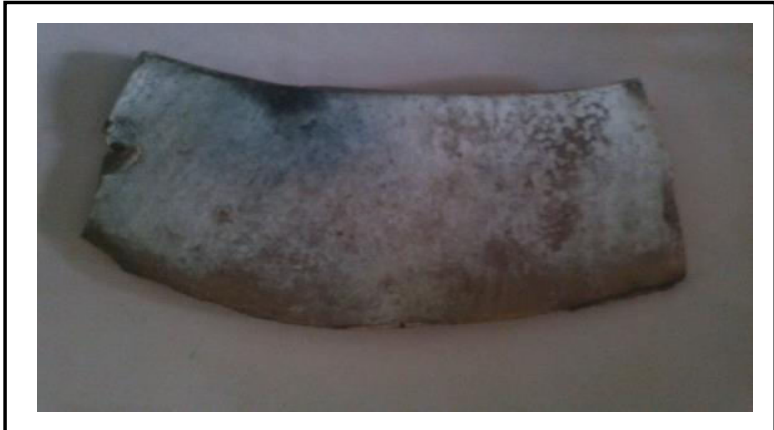

Fig.3. Sheath in the compressed state.

The plate is then punched or cut to have lots of test pieces in accordance with the current standard (Figure 4).

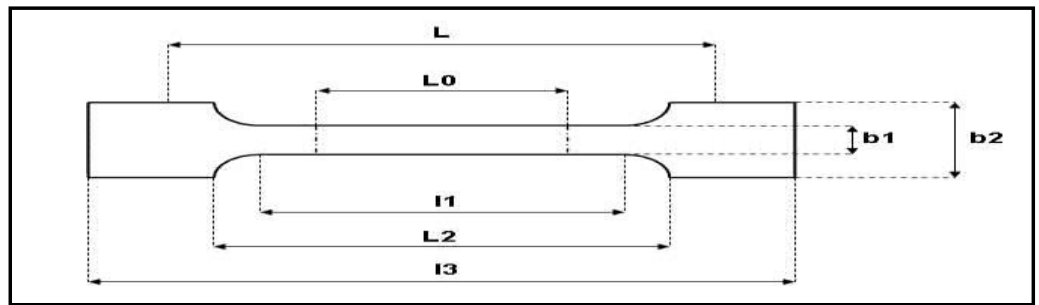

Scheme.1. Standardized specimen.

Table 1. Standardized values of the dimensions of the test specimen.

\begin{tabular}{|l|l|l|l|l|l|l|l|l|l|}
\hline $\begin{array}{l}\text { ISO } \\
527-2\end{array}$ & $1 \mathrm{BA}$ & $\begin{array}{l}\mathrm{I}> \\
75\end{array}$ & $\begin{array}{l}\mathrm{I}=30^{ \pm} \\
0.5\end{array}$ & $\begin{array}{l}\mathrm{b}_{2}=10^{ \pm} \\
0.5\end{array}$ & $\begin{array}{l}\mathrm{b}_{1}=5^{ \pm} \\
0.5\end{array}$ & $\begin{array}{l}\mathrm{h}> \\
2\end{array}$ & $\begin{array}{l}\mathrm{L}_{0}=25^{ \pm} \\
0.5\end{array}$ & $\begin{array}{l}\mathrm{L}_{2}+2 ; \\
\mathrm{L}_{2}=58^{ \pm}\end{array}$ & $\begin{array}{l}\text { Dumbb } \\
\text { ell }\end{array}$ \\
\hline
\end{tabular}

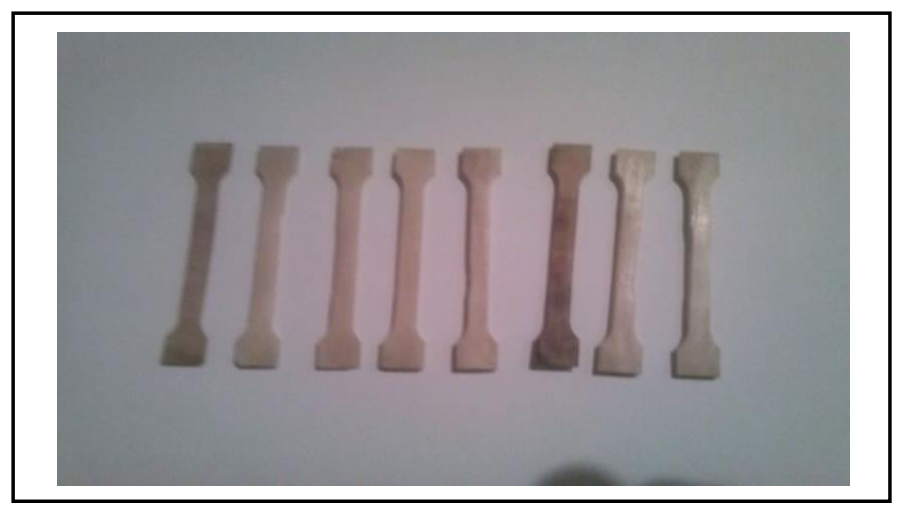

Fig.4. Tubes of traction.

The objective of our first experiment is to verify the advanced assumptions and to acquire positive classification and explore criteria in mechanical characteristics such as the maximum breaking stress, the relative strain and Young's modulus of virgin material [13]. To this end, the flank is cut out according to $45^{\circ}$ angle of fibers direction in four test 
specimens in ISO 527-2Standards, type 1BA and form "HALTERE "(table 1) and des traction tests are made on these specimens to test the reactivity of the virgin material to the solicitations exercised.

\subsection{Process of characterization}

The test bench used is a machine which is adapted both to quality control and to research and develop for various applications. Its modular system provides an optimum solution for demanding testing requests.

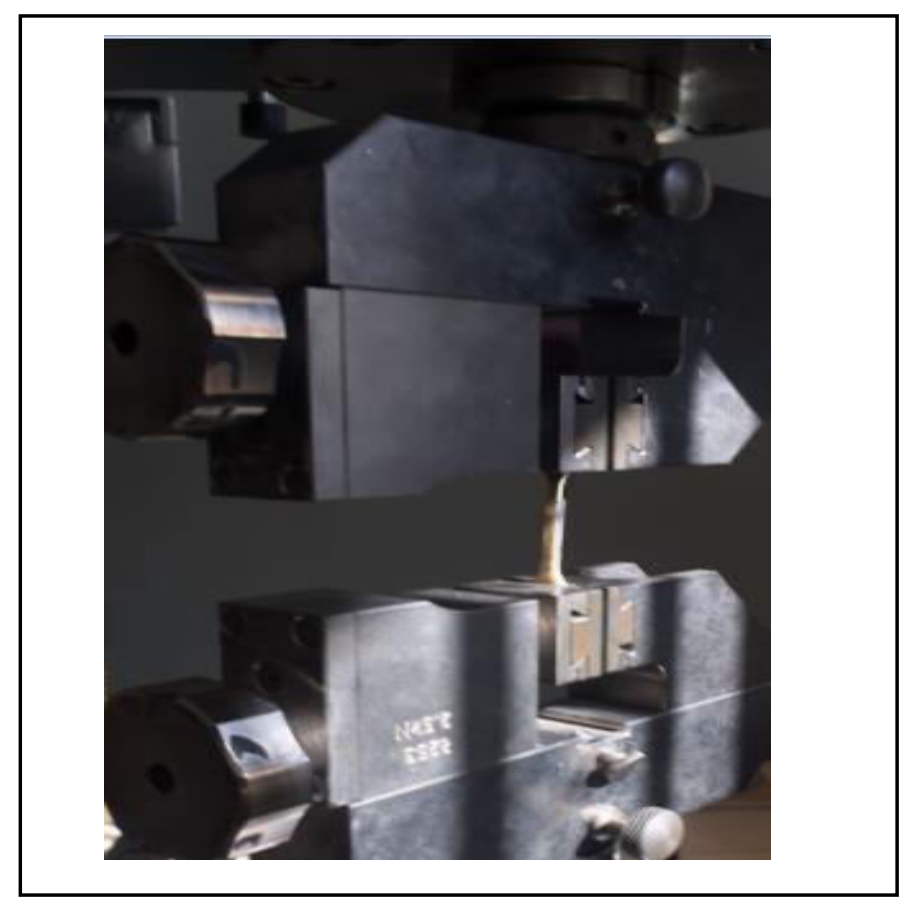

Fig.5. Traction Machine "AllroundLine"

Regardless of the load applied to the test piece, this traction machine has a test speed of 0.00005 to $3000 \mathrm{~mm} / \mathrm{min}$. The speed of the test machine is independent of the test force.

The traction machine rise test loads up to $250 \mathrm{kN}$. The test space height is $1030 \mathrm{~mm}$ to 2560 Mr.

Not requiring the addition of any extra cards, it can be used with a commercial PC or laptop. 


\subsection{Experimental Results}

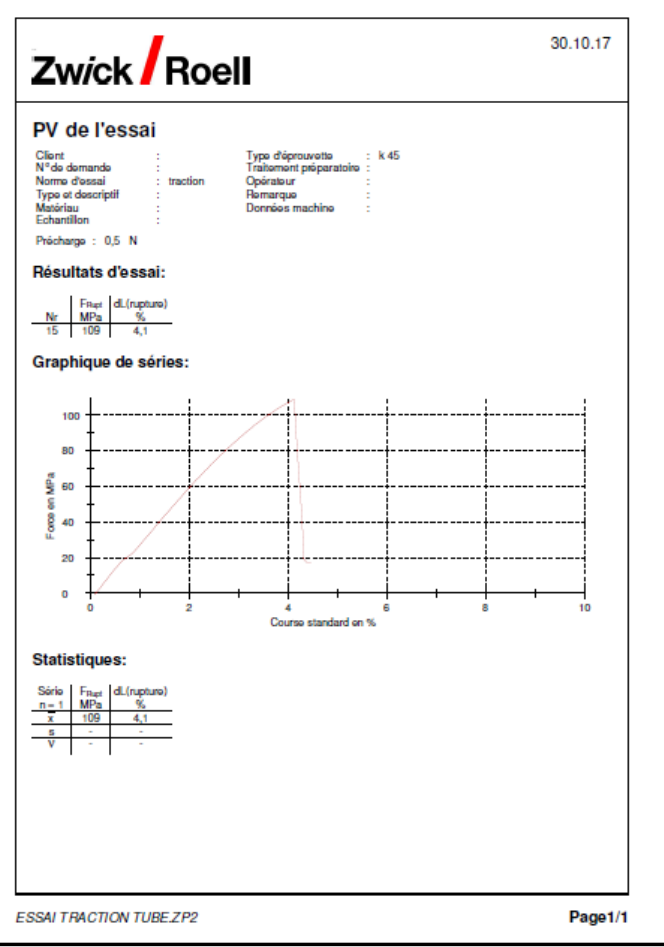

Fig.6-A. Stress-elongation diagram "EProof No. 1"

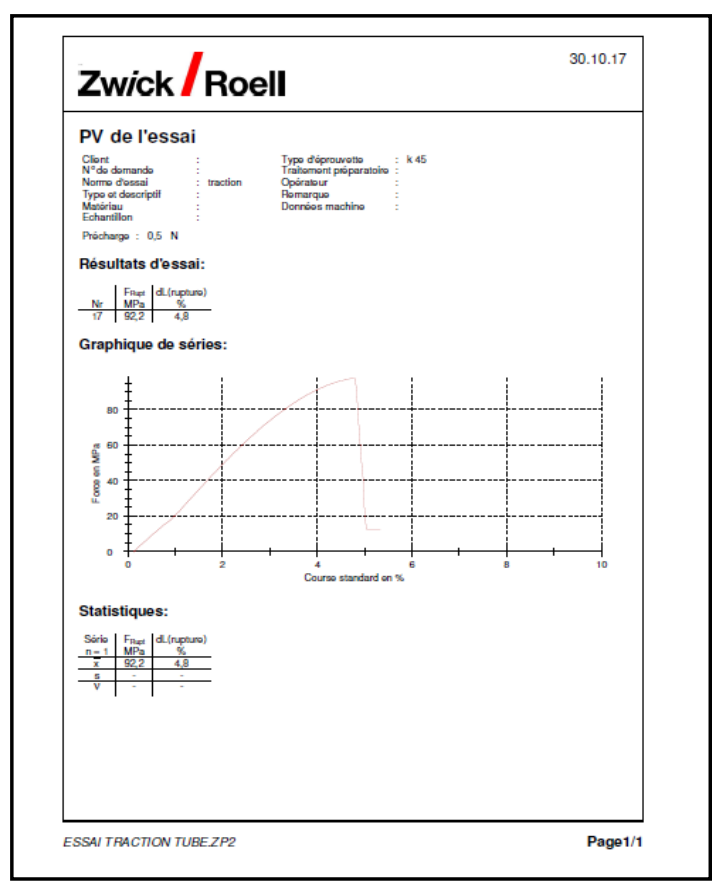

Fig.6-B. Stress Diagram-Elongation "EProof No. 2" 


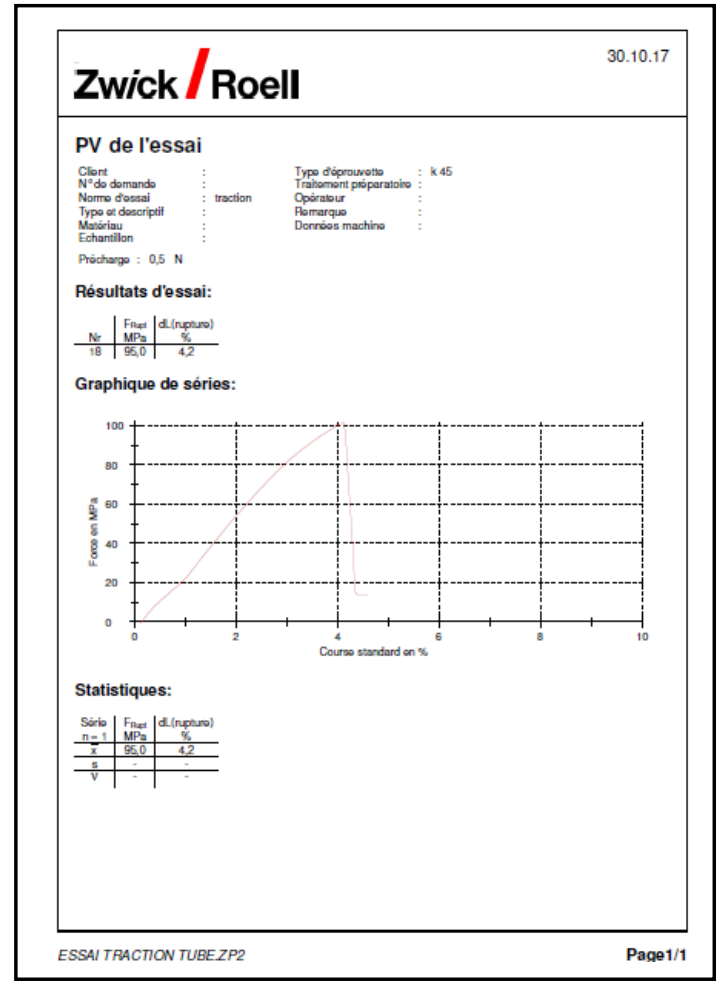

Fig.6-C. Stress-elongation diagram "EProve No. 3"
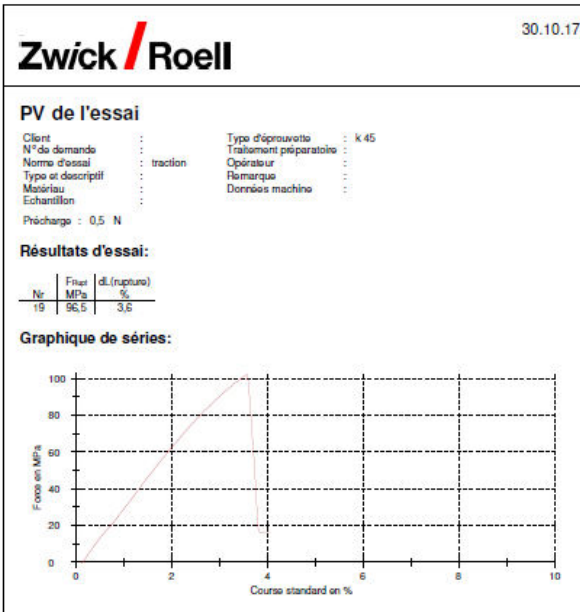

Statistiques:

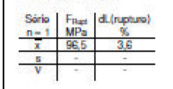

ESSAI TAACTION TUBE.ZP2

Page 1/1

Fig.6-D. Stress-elongation diagram "EProof No. 4" 


\subsection{Comments}

We can summarize by these remarques :

Demonstration of an intrinsic elastic behavior for this chosen direction of cutting specimens;

Identical reactivities of the virgin material to tensile stresses in similar conditions of experience during the traction test similar to the elastic behavior of the biomaterial (Figures $6)$;

Elastic behavior, characterized by the reversibility of strains during the suppression of stresses, is manifested only for constraints less than a limit value, noted "Re" which is called the elasticity limit, as shown in the figure above. However, beyond this limit value, the rupture occurs for all test specimens;

In the case of tensile tests on fibres, the ultimate constraint presents a stable shape as shown in the results part. This stems from the fact that the fracture is related to the orientation of pre-existing fibres (Figures 6).

This Type of behavior clearly shows that the biomaterial has a linear elastic behavior and reversible one. Its rupture occurs while it is still in a purely elastic diet.

At the end of the different results of elastic behaviors recorded by the traction diagram, we can see for the direction of the fibers involved $\left(45^{\circ}\right)$ elastic performances such as:

$>$ A limitation of rupture with very striking traction.

$>$ A relatively small displacement.

$>$ A significant module of longitudinal elasticity.

Also, this biomaterial does not undergo any permanent plastic deformation or necking before it ruptured: It is a rigid and fragile material (Figure 6).

As well this biomaterial can play, through all these optimum indicators, an important role in the bio-loading of other polymer materials and contribute, subsequently, in a respectful manner to the environment by the valorisation of organic waste, to a promotion of the Biodiversity 14].

\section{Conclusion}

The development of more environmentally friendly materials has become a major concern for the industrial world and this responds to a growing society demand. Currently, the research axes on these materials relate to the materials Bio-sourced, biodegradable materials and recycled materials.

In this intention, we were able to contribute to the elastic characterization of a virgin material of animal origins by cutting of the test specimens depending on the orientation of its internal fibers and then testing its tensile strength on a traction bench under similar experience conditions. It is noted that in these tests the material underwent several extension tests and the most significant experimental values were selected.

The reactivity of the biomaterial at tensile stresses generated a similar elastic intrinsic behavior, knowing that four registered behaviors are likely to be present by their related characteristics i.e., maximum resistance to rupture, relative displacement and Young's modulus.

This study has for objective the development of typological classification of the virgin biomaterial according to its mechanical characterization. It shows that biomaterial has characteristics mechanical qualities according to the fibers orientation sense of the material: Anisotropic behavior is judged very favorable to the development of the bio-loads of animal origin for technological innovation of certain polymeric materials [6]. 
In terms of sustainable development, two main approaches will be developed in the research axis: The development of recycling animal's organ in end of life through improved identification performances and the development of bio-loaded materials of renewable resources from organic biomass.

\section{Scientific barriers}

The development of bio based, and biodegradable materials requires the development of specific tests to evaluate the biodegradation of the formulated materials. The end of life by composting must be maintained regardless of the physical properties of the materials and the surface treatments made. The development of materials from secondary first resources requires the obtaining of increasingly important purity in order to aim at high value-added applications.

\section{References}

1. A. KOUADRI, S. CRETIN, (2007): "Inseparable evolutions".

2. E. BRETAGNE, J. BREARD, v. Manasiya and V. Verney, (2012): Eco-Materials: The materials Go Green ", No. 100, 367-368.

3. D. Lice, (1991): (Shell chemistry), "economics-Ecology of Plastics Recycling", symposium of the French Group of studies and Applications of Polymers, Douai, 3843.

4. K. HALADA, (1992) : Bull. Jpn. Inst. Metals No. 31, 505-512.

5. L. AUGIER, (2007): "Study of the elaboration of PVC/wood composite materials from carpentry waste: formulation, characterization, durability and recyclability". Vol. 2507, 11-12.

6. M. JAMMOUKH, K. Mansouri and B. Sadeghi, (2016): Experimental study of the elastic behaviour of a resource bio-load Renewable CSR-2016, 1, 61-66.

7. There. AGARI, Mr. SHIMADA. AND A. UEDA, (1997): Polymer, Vol. 38, $\mathbf{N}^{\circ} \mathbf{1 1}$, 2649-2655.

8. Jc. Angola, Y. FUJITA, T. SAKAI, T. INOUE, (1988): "Compatibilizer-aided toughening in polymer blends consisting of brittle particles dispersed in a ductile polymer matrix", Journal of Polymer Science, 26 (4) 807-816.

9. F.S. BATES, (1991): "Polymer-polymer phase behaviour", Science, 251 (4996), 898905.

10. C.A. BERNARDO, a.m. CUNHA AND M.J. OLIVEIRA, 1996: The Department of Polymer Engineering, Universidade Do Minho), "The Recycling of thermoplastics: Prediction of The Properties of mixtures of Virgin and reprocessed Polyolefins", 4800 Guimaraes, Portugal, Polymer Engineering and Science, Vol. 36, No. 4.

11. A.S. NEFF (FIBL), B. HUMI and R. STREIFF, (2015): The importance of horns in cows. Vol. 6, 1691

12. K. HALADA, ,(2003): "Progress of Ecomaterials Towards a sustainable society, Current Opinion in Solid State and Materials Science, Vol. 7, 209-216-368.

13. E. BRETAGNE, J. BREARD, v. Manasiya and V. Verney, (2012): Eco-Materials: The materials Go Green ", No. 100, 367-368.

14. ALLRED, (1996): Recycling process to scrap composites and Prepregs, Int. Sampe SyPm. Exhib, 41, 21-31. 